\title{
Influence of Construction Materials and Building Orientation on Building Thermal Load in Hot and Dry Tropical Climate
}

\author{
Ousmane Coulibaly ${ }^{1}$, Frederic Kuznik ${ }^{2}$, Dominique Baillis ${ }^{3}$ and Abdoulaye Ouedraogo ${ }^{4}$ \\ 1. LPCE (Laboratoire de Physique et Chimie de l'Environnement), Université de Ouagadougou, Ouagadougou 03, 03 BP 7021, \\ Burkina Faso \\ 2. CETHIL (Centre de Thermique de Lyon), UMR (Unité Mixte de Recherche) 5008, INSA (Institut National des Sciences et \\ Appliquées), Campus La Doua-LyonTech, Villeurbanne Cedex 69621, France \\ 3. LaMCoS (Laboratoire de Mécanique des Contacts et des Structures), UMR (Unité Mixte de Recherche) 5259, INSA (Institut \\ National des Sciences Appliquées), Campus La Doua-LyonTech, Villeurbanne Cedex 69621, France \\ 4. LETRE (Laboratoire des Énergies Thermique et Renouvelable), Université de Ouagadougou, Ouagadougou 03, 03 BP 7021, \\ Burkina Faso
}

Received: September 07, 2015 / Accepted: October 08, 2015 / Published: December 31, 2015.

\begin{abstract}
This paper is concerned with the determination of the thermal energy performances of individual houses built with " $H$ " shape bricks in hot and dry tropical climate (different cities of Burkina Faso and the city of Bamako in Mali). The bricks' matrices include three void spaces which are filled during construction with either clay-grass mixture or with entirely clay matter. After measuring the diffusivity of the clay matter and cement bricks samples utilizing the Flash method, we determine the " $\mathrm{H}$ " shape bricks" thermal equivalent conductivity using the HEAT software. The house, modeled utilizing the TRNSYS software, reveals that, besides their economical and environmental advantages, houses constructed with " $\mathrm{H}$ " shape bricks filled with clay, show approximately the same energy consumption patterns as void cement bricks houses. On the other hand, houses built utilizing " $H$ " shape bricks filled with clay-grass mixture, which have low thermal conductivity, show a reduced air conditioning load. We also study the influence of the building orientation on the energy consumption.
\end{abstract}

Key words: “H” shape bricks', clay-grass bricks, clay bricks, Flash method.

\section{Nomenclature}

\section{Latin Letters}

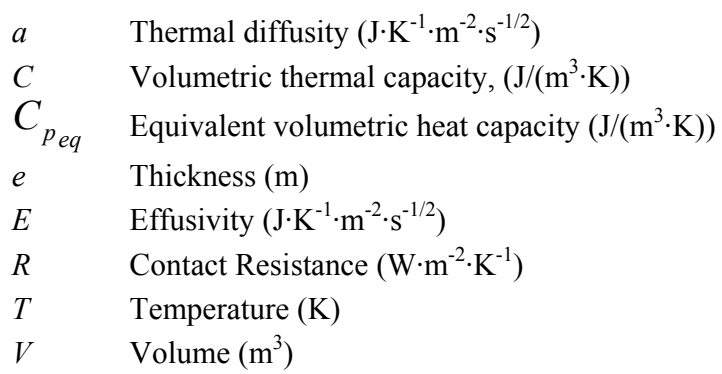

Corresponding author: Ousmane Coulibaly, Dr., teacher researcher, research fields: materials and energy efficiency, thermal and energy regulation in building.

$$
t \quad \text { Time (s) }
$$

Greek Letters

$$
\begin{array}{ll}
\phi & \text { Power dissipated in the hot plate }\left(\mathrm{W} / \mathrm{m}^{2}\right) \\
\lambda & \text { Thermal conductivity }\left(\mathrm{W} \cdot \mathrm{m}^{-1} \cdot \mathrm{K}^{-1}\right) \\
\Delta T & \text { Temperature gradient }(\mathrm{K}) \\
\rho & \text { Volumetric heat capacities }\left(\mathrm{J} /\left(\mathrm{m}^{3} \cdot \mathrm{K}\right)\right)
\end{array}
$$

\section{Introduction}

The thermal efficiency of building in Burkina Faso in particular and in sub-Saharan Africa in general is poor due essentially to the lack of thermal energy regulation or building energy code policy. The 
consequences are excessive energy load for air conditioned buildings. As a matter of fact, the energy consumption in the public and private buildings in the tertiary sector in sub-Saharan Africa is estimated to amount to $250-450 \mathrm{kWh} / \mathrm{m}^{2}$ air conditioned/year, depending on the story level [1]. To bring these expenditures into control, it is important to gather basic scientific data which can influence the decision makers to take action. This investigation is the first leg of a broader undertaken we hope, will take us up to the conception of a coherent energy regulation policy. Previous works have shown that, depending on the country, between $30 \%$ and $45 \%$ [2] of energy economy can be realized, especially in air conditioning processes. Unfortunately, some of these studies take in account only few parameters and besides, assume steady state approximations. In the actual investigations, dynamic software which has been shown to be quite effective in analysing these new types of composite construction materials like the " $H$ " shape bricks, are been used. This model of constructions in " $H$ " shape bricks were engineered by the Malian architect Gaoussou Traoré [3] (intellectual property, WO/2005/033429) and presented at the international salon held at Geneva, Switzerland in 2005. A project for the construction of new "H" shape bricks houses has been initiated by the government, with the aim of providing descend and energy efficient habitats for low income people. These investigations are useful to check the government claims and avoid high costs and lengthy experimentations. The computations are based on software analysis inspired by the works of: Coulibaly and Toguyeni [4], Coulibaly, et al. [5],
Toguyeni, et al. [6], Kuznik, et al. [7], Lehmann, et al. [8] and Gao, et al. [9].

First of all, we make measurements of the diffusivity and heat capacity of clay matter and cement bricks samples, then we determine the thermal equivalent conductivity of the " $H$ " shape bricks using the HEAT software, finally, we evaluate and analyse the thermal performances of an individual house utilizing the TRNSYS software.

\section{Diffusivity and Heat Capacity Measurements}

The measurements of the diffusivity and the heat capacity took place, respectively at Influtherm, an industrial center, utilizing the Flash method and at CETHIL, INSA (Lyon Thermal Science Laboratory, National Institute of Applied Sciences, France) utilizing a mean temperature diffusivity meter. The hot and dry Sahelian temperature fluctuations patterns are simulated by making the measurements at temperature intervals varying between $13 \pm 2{ }^{\circ} \mathrm{C}$ and $42 \pm 2{ }^{\circ} \mathrm{C}[10]$. The results are shown in Table 1 below. Their precisions are, respectively estimated to $10 \%$ and $6.5 \%$ for the diffusivity and the heat capacity. To validate these results, we have computed the diffusivity of the clay matter and cement bricks samples, utilizing the thermal data given by RT 2000 (thermal regulation code in building for year 2000, France) [11]. The values found vary between 0.30 $\mathrm{mm}^{2} / \mathrm{s}$ and $0.68 \mathrm{~mm}^{2} / \mathrm{s}$ for the clay matter and between $0.62 \mathrm{~mm}^{2} / \mathrm{s}$ and $0.82 \mathrm{~mm}^{2} / \mathrm{s}$ for the cement bricks, their relative humidity being, respectively equal to $0.73 \%$ and $1.4 \%[10]$.

Table 1 Measured thermal properties.

\begin{tabular}{llllcl}
\hline Samples & Temperature $\left({ }^{\circ} \mathrm{C}\right)$ & Diffusivity $\left(\mathrm{mm}^{2} / \mathrm{s}\right)$ & Density $\left(\mathrm{kg} / \mathrm{m}^{3}\right)$ & Heat capacity $(\mathrm{J} /(\mathrm{kg} \cdot \mathrm{K}))$ & Conductivity $(\mathrm{W} /(\mathrm{m} \cdot \mathrm{K}))$ \\
\hline $\mathrm{AR} 1^{a}$ & 12.42 & 0.38 & 1,360 & 957 & $0.49 \pm 0.05$ \\
$\mathrm{AR} 2^{a}$ & 13.22 & 0.44 & 1,280 & 825 & $0.46 \pm 0.06$ \\
$\mathrm{C}^{a}$ & 13.04 & 0.70 & 1,810 & 762 & $0.97 \pm 0.10$ \\
$\mathrm{AR} 1^{b}$ & 42.75 & 0.35 & 1,360 & 1,080 & $0.51 \pm 0.05$ \\
$\mathrm{AR}^{b}$ & 42.70 & 1,280 & 852 & $0.50 \pm 0.06$ \\
$\mathrm{C}^{b}$ & 42.62 & 0.43 & 1,810 & 852 & $1.20 \pm 0.12$ \\
\hline
\end{tabular}

AR1: clay matter 1; AR2: clay matter 2; C: cement bricks; $a$ : measure at low temperature; $b$ : measure at high temperature. 


\section{The HEAT Software and Construction Materials Properties}

\subsection{The HEAT Software and the " $H$ " Shape Bricks Model}

The HEAT software simulates thermal bridge and computes the equivalent thermal conductivity of composite walls, assuming either steady or transient conditions. HEAT2 and HEAT3 deal, respectively with two and three dimensions simulations. The software has been developed at LUNDT University based on finite volume analysis with variable grid space and capable of solving many configuration problems [12].

The governing heat conduction equation in Cartesian coordinates is modeled as follows:

In two dimensions:

$$
\frac{\partial}{\partial x}\left(\lambda_{x} \cdot \frac{\partial T}{\partial x}\right)+\frac{\partial}{\partial y}\left(\lambda \cdot \frac{\partial T}{\partial y}\right)+I(x, y, t)=C \frac{\partial T}{\partial t}
$$

where, $I\left(\mathrm{~W} / \mathrm{m}^{3}\right)$ represents the internal heat sources. The conductivity along the $\mathrm{x}$ and $\mathrm{y}$ axes is assumed equal; $C=\rho \cdot C_{p} \quad\left(\mathrm{~J} /\left(\mathrm{m}^{3} \cdot \mathrm{K}\right)\right)$ is the volumetric thermal capacity. The source terms are often inexistent and in steady state conditions, the second member is nil.

In three dimensions:

$\frac{\partial}{\partial x}\left(\lambda \cdot \frac{\partial T}{\partial x}\right)+\frac{\partial}{\partial y}\left(\lambda, \frac{\partial T}{\partial y}\right)+\frac{\partial}{\partial z}\left(\lambda \cdot \frac{\partial T}{\partial z}\right)+I(x, y, z, t)=C \frac{\partial T}{\partial t}$

Two types of boundary conditions are often used: the first condition is linked to the surface resistance and the second to functional time dependence, $f(t)$.

$$
\begin{gathered}
T_{b s}(t)-\left.T\right|_{\text {surf }}=\left.R \cdot(-\lambda) \cdot \frac{\partial T}{\partial n}\right|_{\text {surf }} \\
\left.(-\lambda) \cdot \frac{\partial T}{\partial n}\right|_{b s}=f(t)
\end{gathered}
$$

If the contact is perfect between two materials, we have:

$$
\left.\left(-\lambda_{1}\right) \cdot \frac{\partial T}{\partial n}\right|_{1}=\left.\left(-\lambda_{2}\right) \cdot \frac{\partial T}{\partial n}\right|_{2}
$$

On the other hand, if the contact is not perfect, then:

$$
\left.\left(-\lambda_{1}\right) \cdot \frac{\partial T}{\partial n}\right|_{1}=\frac{\left.T\right|_{2}-\left.T\right|_{1}}{R_{i n s}}=\left.\left(-\lambda_{2}\right) \cdot \frac{\partial T}{\partial n}\right|_{2}
$$

We show in Fig. 1a, a photo of a "H" shape bricks' wall in construction and in Fig. 1b, a model of the bricks and dimensions. The measurements' error is $\pm 2 \mathrm{~mm}$. The input data are the conductivity and the volumetric heat capacity of the composite materials. We assume a one dimensional heat conduction equation and set conditions defined in Fig. 1c.

Knowing the temperature difference between the inner and outer and the thickness of the composite material, we can infer its equivalent conductivity, utilizing the following relation:

$$
\lambda_{e q}=\frac{\varphi_{T} \cdot e}{\Delta T}
$$

where, $\varphi_{T}$ is the heat flux $\left(\mathrm{W} / \mathrm{m}^{2}\right), e$ is the thickness (m) and $\Delta T$ is the temperature gradient $\left({ }^{\circ} \mathrm{C}\right)$.

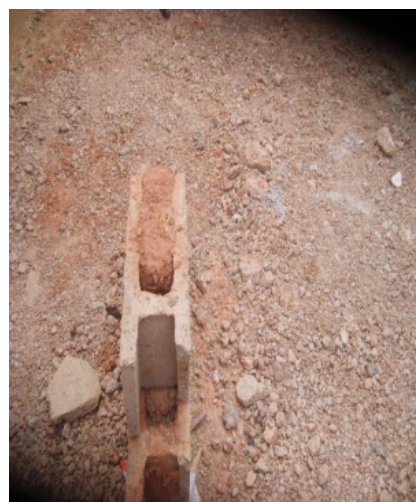

(a)

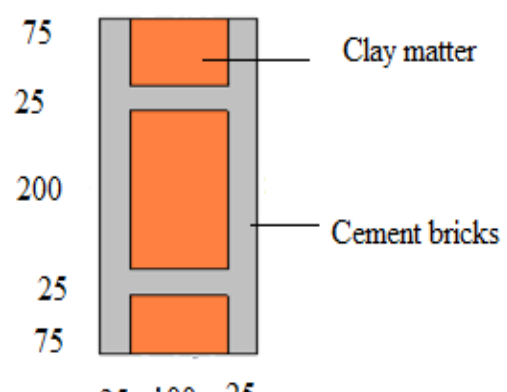

$25 \quad 100 \quad 25$

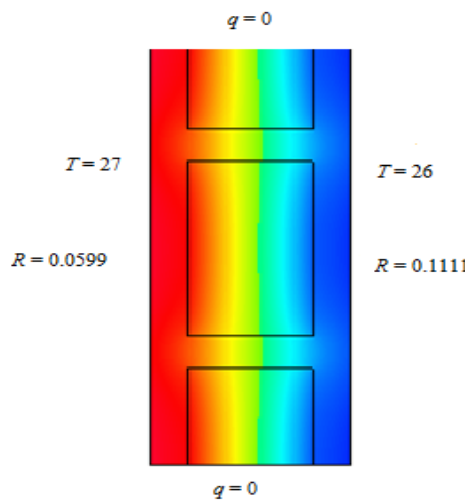

(c)

Fig. 1 Photo of wall in construction, model of "H" shape bricks and boundary conditions. 
We can then compute the equivalent volumetric heat capacity $C_{p_{e q}}\left(\mathrm{~J} /\left(\mathrm{m}^{3} \cdot \mathrm{K}\right)\right)$ as follows: (compact as well as void bricks) comes from IFDD (Francophone Institute for the Durable Development) published data [2].

\section{Modeling with TRNSYS}

\subsection{Description of the Model House}

The actual model (Fig. 2), is a $50 \mathrm{~m}^{2}$ surface area south oriented front door individual house, which is part of a larger government planned lower cost and energy efficient project. It has two bedrooms, a living room and toilets. The walls are $25 \mathrm{~cm}$ " $\mathrm{H}$ " shape bricks made, cement insulated, white inner finish and thick yellow outer finish. It has $15 \mathrm{~cm}$ thick concrete floor, double planes metal-frame wooden doors, while the windows are made of ordinary $4 \mathrm{~mm}$ metal-frame thick glazing, having pure conductance equal to $5.7 \mathrm{~W} /\left(\mathrm{m}^{2} \cdot \mathrm{K}\right)$ and a solar factor equal to 0.85 . The roof is made of $20 \mathrm{~cm}$ thick concrete with $15 \mathrm{~cm}$ chipboard enclosures.

\subsection{Multizone Modeling}

The modeling is performed over one year period with $1 \mathrm{~h}$ time step, utilizing the TRNSYS software [13]. In order to have refined results, the building is subdivided into six (6) zones which are: zone 1, living room; zone 2, terrace; zone 3 , joint passage; zone 4 , bedroom 1 ; zone 5 , bedroom 2 ; zone 6 , toilets.

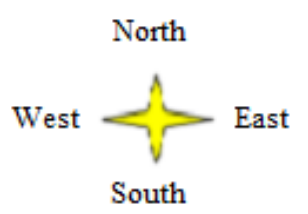

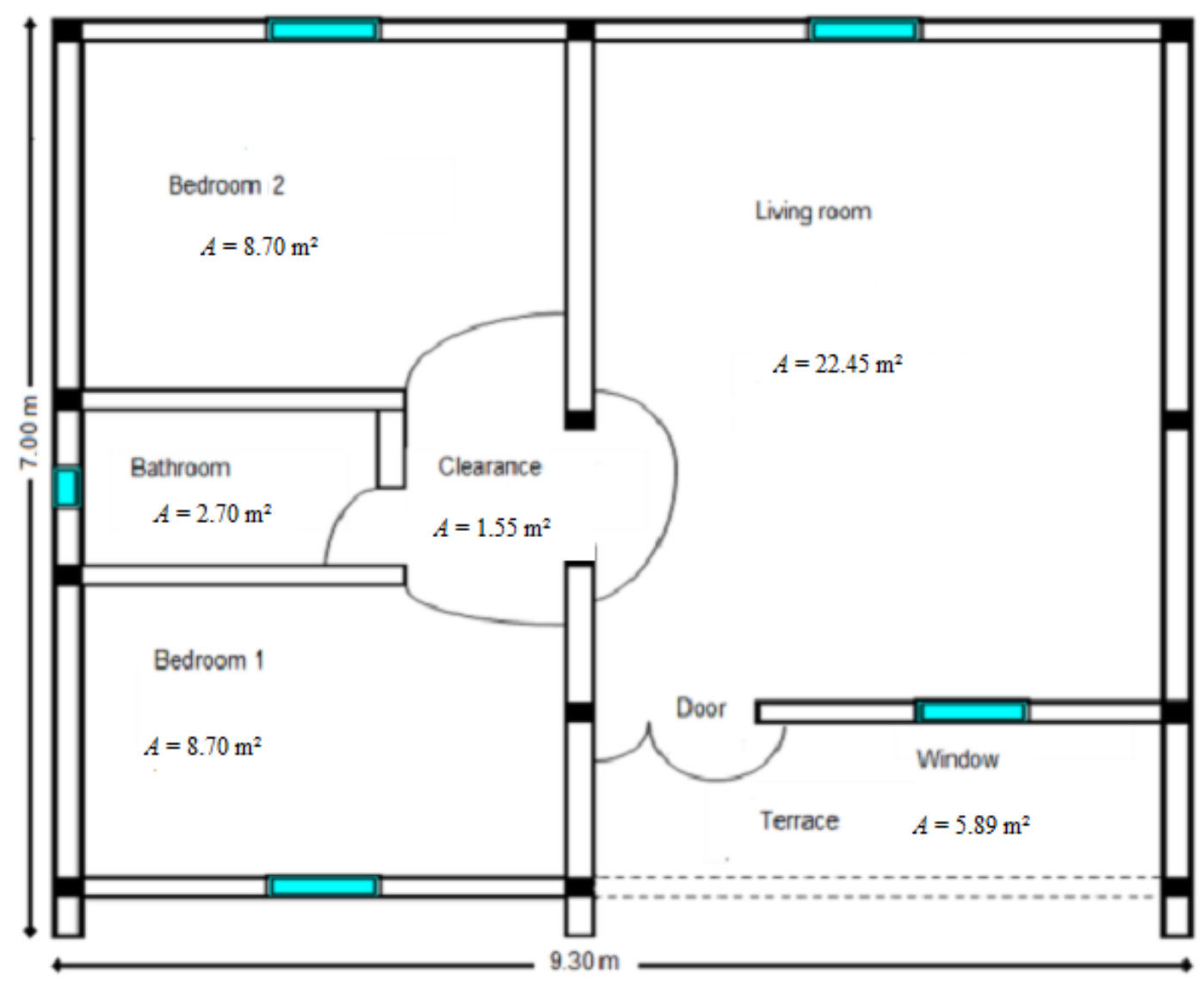

Fig. 2 Building configuration. 


\subsection{Meteorological Data}

The building is location at Ouagadougou. The city Meteonorm meteorological data compiled by TRNSYS in its 16.1 version are utilized for the simulation [13]. Similar data for three additional towns in Burkina Faso and the city of Bamako, Mali, are also concerned, in order to compare their building sensible thermal loads.

\subsection{Internal Heat Load and Regulation Equipments}

We assume that, the air conditioner starts running when the indoor air temperature is greater than $27{ }^{\circ} \mathrm{C}$ with $50 \%$ relative humidity [14]. The ventilation and the infiltration air are set to one volume per hour. Scenarios for weekdays and weekend uses for the bedrooms and living room have been created. The number of occupants is four in the living room and two in each bedroom. For lighting, a fluorescent lamp whose power is $8 \mathrm{~W}$ is used in each room [2]. The living room holds a television $(60 \mathrm{~W})$, and a refrigerator $(70 \mathrm{~W})$ with a duty cycle of $100 \%$, and a DVD player $(150 \mathrm{~W})$ with load factor of $40 \%$ [2].

\section{Model Results and Discussions}

\subsection{Computation of Energy Consumed in Different Cities}

Fig. 3 shows the sensible cooling loads obtained for four synoptic stations in Burkina Faso and Bamako in Mali. The five figures are quite similar, with picks between March and June: the smallest loads appear between July and September due to the raining season, followed by an increase in October and finally a load decrease starting in November. The synoptic station of Bobo-Dioulasso shows the lowest sensible cooling load maxima of all stations. On the other hand, notice that, the latent load increases from May to October during the raining season (Fig. 4). From November to March, period during which the percentage of the relative humidity is small, the latent cooling load is approximately nil depending on the station. It is known

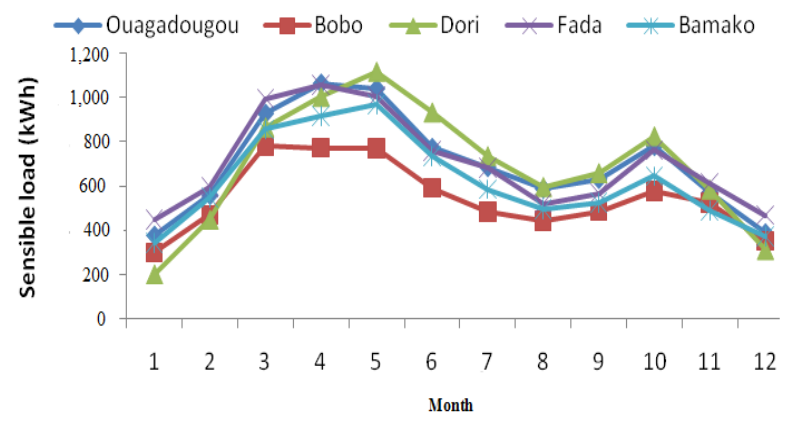

Fig. 3 Sensible cooling load in living rooms.

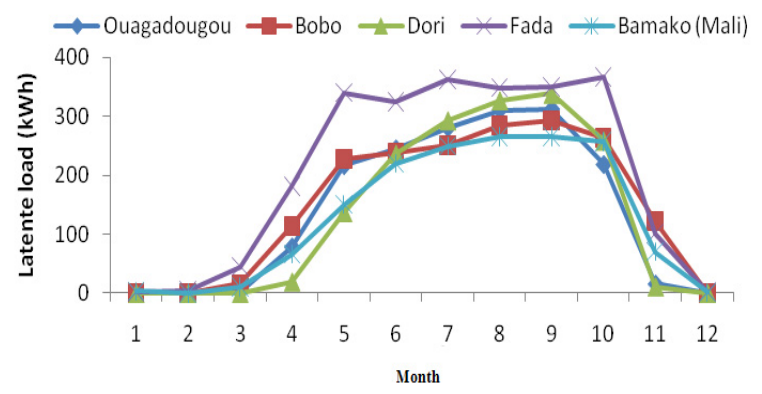

Fig. 4 Latent cooling load in living rooms.

that, in dry hot climate like that of the Sahelian region, the air conditioning process is accompanied by a dehumidification of the air while during the hot and dry months, March and April, the space needs to be humidified instead.

\subsection{Influence of Construction Materials on Sensible Air Conditioning Load}

Fig. 5 shows the influence of the wall construction materials on the sensible air conditioning load

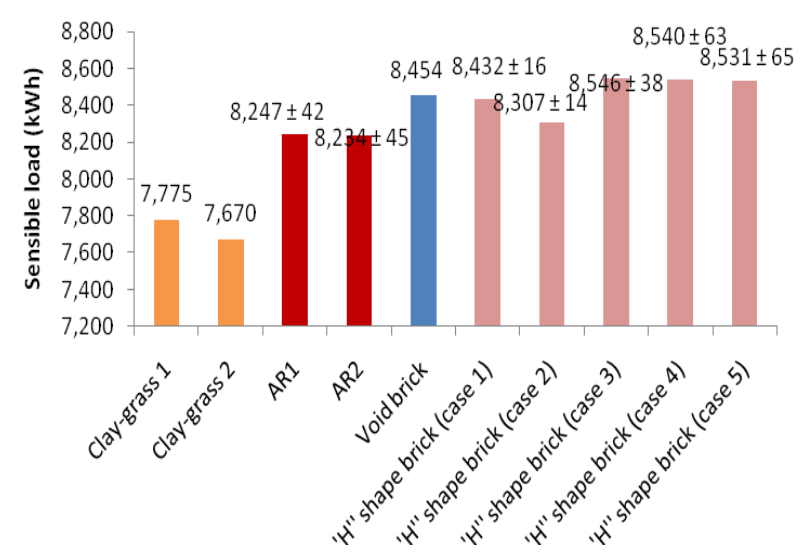

Fig. 5 Influence of wall construction materials on sensible cooling load. 
Table 2 Construction materials thermophysical properties.

\begin{tabular}{llll}
\hline Materials $(\mathrm{L}=$ literature; $\mathrm{M}=$ measured) & $\begin{array}{l}\text { Thermal conductivity } \\
(\mathrm{W} /(\mathrm{m} \cdot \mathrm{K}))\end{array}$ & $\begin{array}{l}\text { Density } \\
\left(\mathrm{kg} / \mathrm{m}^{3}\right)\end{array}$ & $\begin{array}{l}\text { Heat capacity } \\
(\mathrm{J} /(\mathrm{kg} \cdot \mathrm{K}))\end{array}$ \\
\hline Compact brick (L) & 1.1 & 2,100 & 880 \\
Compact brick (M) & $0.97 \pm 0.10$ & $1,810 \pm 37$ & $762 \pm 50$ \\
Clay-grass 1 (L) & 0.17 & 600 & 1,249 \\
Clay-grass 2 (L) & 0.12 & 400 & 1,000 \\
Mud-AR1 (M) & $0.49 \pm 0.05$ & $1,360 \pm 38$ & $957 \pm 62$ \\
AR2 (M) & $0.47 \pm 0.06$ & $1,280 \pm 45$ & $833 \pm 54$ \\
Void brick & 0.67 & 1,250 & 880 \\
\hline "H" shape bricks (simulated with HEAT): & \multicolumn{3}{l}{} \\
\hline Case 1: clay-grass 1 and compact brick (L-L) 1,303 $\pm 7,971 \pm 18$ & $0.68 \pm 0.02$ & $971 \pm 18$ \\
Case 2: clay-grass 2 and compact brick (L-L) & $0.54 \pm 0.02$ & $1,303 \pm 7$ & $901 \pm 13$ \\
Case 3: AR1 and compact brick (M-L) & $0.80 \pm 0.06$ & $1,197 \pm 6$ & $913 \pm 67$ \\
Case 4: AR1 and compact brick (M-M) & $0.78 \pm 0.08$ & $1,571 \pm 38$ & $866 \pm 56$ \\
Case 5: AR2 and compact brick (M-M) & $0.76 \pm 0.08$ & $1,528 \pm 42$ & $795 \pm 52$ \\
\hline
\end{tabular}

consumed during the hottest months, i.e., March, April, May, June and October. As expected, the clay-grass house is more efficient followed by the mud house. We notice also that, when the " $\mathrm{H}$ " shape brick is made of mud, cases 3-5, the heat load is greater than that of void brick house. In the meantime, a clay-grass house, case 1 , has the same heat load than void brick house. But, the clay-grass mixture reduces the need for air conditioning. The influence of the errors due to the values of the construction materials thermal characteristics shown in Table 2 on the thermal load has been evaluated. Remember that, the properties of the construction materials have been taken from the literature and are not concerned with the stated errors.

\subsection{Influence of Rotation and Construction Materials on Sensible Heat Load}

We keep the same assumption as above, i.e., both the roof and the floor are insulation while the wall is not. A step size angle of $30{ }^{\circ} \mathrm{C}$ is utilized together with East orientation. Due to the amount of solar irradiation in hot tropical climate, the rotation of the building has a tremendous influence on the thermal heat load. This fact can be seen from the histograms obtained for bedrooms 1 and 2 which have the same volume but different orientation (Fig. 6). Fig. 7 shows the influence of the orientation on the differences of sensible heat consumed in the living room, on one hand, between the void bricks and clay-grass mixture, and on the other hand, between void bricks and the " $\mathrm{H}$ " shape bricks. As seen, the consumption differences vary, function of the orientation angle. The conclusion is that, the thermal energy consumption is both function of the angle and the type of construction material involved.

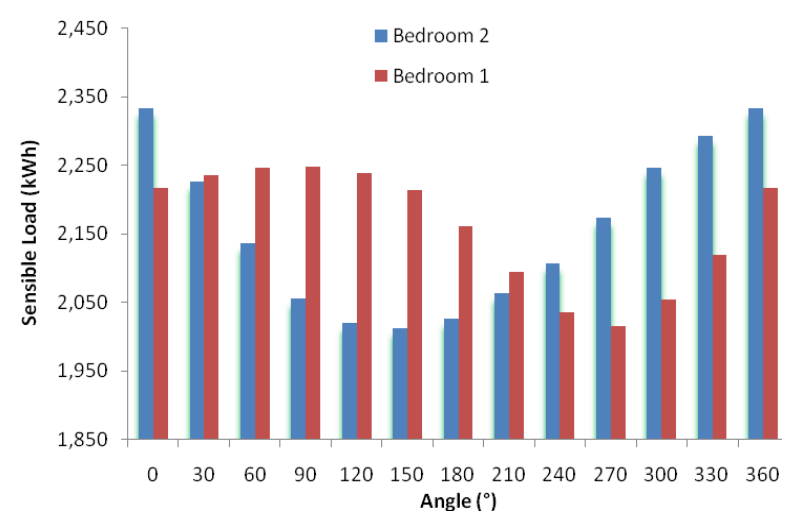

Fig. 6 Influence of rotation on sensible heat load in bedrooms 1 and 2 .

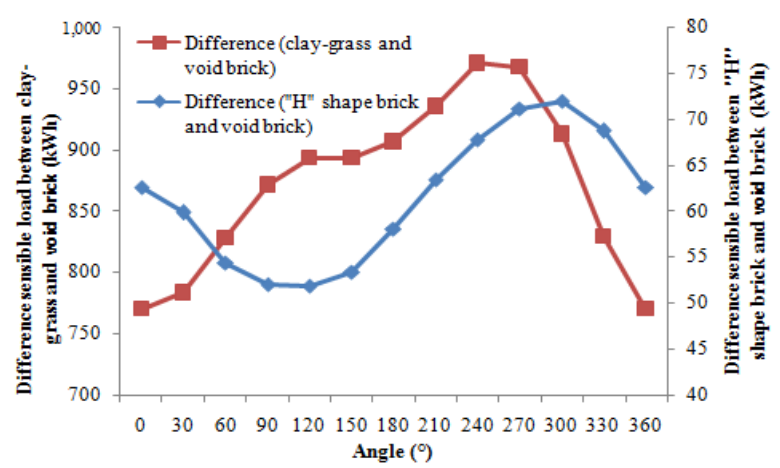

Fig. 7 Influence of orientation on the differences of sensible load in living rooms. 


\section{Conclusions}

The main conclusion of the actual work is that, both the type of construction material and the building orientation influence its thermal load consumption. Among all the investigated material samples, the " $\mathrm{H}$ " shape brick filled with clay-grass mixture shows not only economical and environmental advantages but also consumes the same thermal heat as void brick building. This is very important for the entire Sahelian region, because we spend huge amounts of our hard gained currencies paying for the price tag of not only imported fossil fuel but also for the cement utilized for the design of the void bricks. As previously said, the actual study is part of a much larger undertaken which objective is to gather necessary and enough scientific data for the conception of the country's energy regulation code policy. Therefore, our hope is that, this effort obtains some support and then continues with research topics covering broader scope including, refining the " $\mathrm{H}$ " shape bricks, looking for new local construction and appropriate insulation materials. Of course, economical investigation of the all process is necessary to make sure the entire operation is feasible.

\section{References}

[1] IFDD (Francophone Institute for the Durable Development). 2001. "Ventilation and Air-Conditioning Systems, PRISM.” IFDD. Accessed November 12, 2015. http://www.ifdd.francophonie.org/ressources/ressources-p ub.php?id=2\&annee $=2001$.

[2] IFDD. 2002. "Energy Effectiveness of Air-Conditioning in Tropical Area." Design of the New Buildings 1. Accessed November 12, 2015. http://www.ifdd.francophonie.org/ressources/ressources-p ub.php?id=4\&annee $=2002$.

[3] Traoré, G. 2005. "Construction Method Involving the Use of Cast Concrete Blocks Comprising One or Two H-Shaped Forms by Way of Formwork for Adobe (Earth) Construction.” World Organization Intellectual Property, WO/2005/033429.

[4] Coulibaly, O., and Toguyeni, D. Y. K. 2014. "Eco
Insulation Materials: Reduction of Cooling Loads of a House Made of Breeze Block or Laterite in a Dry Tropical Climate." Journal of Energy and Power Engineering 8 (7): 1246-50.

[5] Coulibaly, O., Ouedraogo, A., Kuznik, F., Baillis, D., and Koulidiati, J. 2012. "Investigation of Building Energy Autonomy in the Sahelian Environment." IOP Conf. Series: Materials Science and Engineering 29 (1): 012013.

[6] Toguyeni, D. Y. K., Coulibaly, O., Ouedraogo, O. A., Koulidiati, J., Dutil, Y., and Rousse, D. 2012. "Study of the Influence of a Roof Insulation from Local Materials on Cooling Loads of a House Build of Clay and Straw." Energy \& Buildings 50 (July): 74-80.

[7] Kuznik, F., Virgone, J., and Johannes, K. 2010. "Development and Validation of a New TRNSYS for the Simulation of External Buildings Walls Containing PCM." Energy and Buildings 42 (7): 1004-9.

[8] Lehmann, B., Güttinger, H., Dorer, V., van Velsen, S., Thiemann, A., and Frank, T. 2010. "Eawag Forum Chriesbach-Simulation and Measurement of Energy Performance and Comfort in a Sustainable Office Building." Energy and Buildings 42 (10): 1958-67.

[9] Gao, Y., Roux, J. J., Zhao, L. H., and Jiang, Y. 2008. "Dynamical Building Simulation: A Low Order Model for Thermal Bridges Losses." Energy and Buildings 40 (12): 2236-43.

[10] Coulibaly, O. 2011. "Contribution to the Development of a Thermal and Energy Regulation of the Buildings in Burkina Faso: Multiparametric Climatic Data and Modeling Thermo-Aerodynamics under CoDyBa and TRNSYS." Ph.D. thesis, University of Ouagadougou Burkina Faso.

[11] Ministry for the Equipments, Transport and Housing. 2000. "RT 2000." Ministry for the Equipments, Transport and Housing. Accessed November 12, 2015. http://www.rt-batiment.fr/.

[12] Blomberg, T. 2000. "HEAT2: A PC-Program for Heat Transfer in Two Dimensions." In Manual with Brief Theory and Examples. Sweden: Lund-Gothenburg Group for Computational Building Physics, Department of Building Physics, Lund University.

[13] Klein, S. A., Beckman W. A., Mitchell, J. W., Duffie J. A., Duffie, N. A., and Freeman, T. L. 2006. User Manual, Solar Energy Laboratory. Madison: University of Wisconsin. TRNSYS Version 16.1.

[14] Givoni, B. 1994. "Building Design Principles of Hot Humid Regions.” Renewable Energy 5 (5-8): 908-16. 